\title{
Short Jute Fiber Reinforced Polypropylene Composites: Effect of Nonhalogenated Fire Retardants
}

\author{
Sk. Sharfuddin Chestee, ${ }^{1}$ Pinku Poddar, ${ }^{1,2}$ Tushar Kumar Sheel, ${ }^{1}$ Md. Mamunur Rashid, \\ Ruhul A. Khan, ${ }^{3}$ and A. M. Sarwaruddin Chowdhury ${ }^{1}$ \\ ${ }^{1}$ Department of Applied Chemistry and Chemical Engineering, Faculty of Engineering, University of Dhaka, Dhaka 1000, Bangladesh \\ ${ }^{2}$ Office of the Chief Chemical Examiner, CID, Bangladesh Police, Mohakhali, Dhaka, Bangladesh \\ ${ }^{3}$ Radiation and Polymer Chemistry Laboratory, Institute of Nuclear Science and Technology, \\ Bangladesh Atomic Energy Commission, G.P.O. Box 3787, Dhaka, Bangladesh
}

Correspondence should be addressed to Pinku Poddar; p.pinku@yahoo.com

Received 1 April 2017; Revised 28 April 2017; Accepted 11 May 2017; Published 27 June 2017

Academic Editor: Emilio Bucio

Copyright (C) 2017 Sk. Sharfuddin Chestee et al. This is an open access article distributed under the Creative Commons Attribution License, which permits unrestricted use, distribution, and reproduction in any medium, provided the original work is properly cited.

\begin{abstract}
Short jute fiber reinforced polypropylene (PP) composites were prepared using a single screw extrusion moulding. Jute fiber content in the composites is optimized with the extent of mechanical properties, and composites with $20 \%$ jute show higher mechanical properties. Dissimilar concentrations of several fire retardants (FRs), such as magnesium oxide (MO), aluminum oxide (AO), and phosphoric acid (PA), were used in the composites. The addition of MO, AO, and PA improved the fire retardancy properties (ignition time, flame height, and total firing time) of the composites. Ignition time for $30 \% \mathrm{MO}$, flame height for $30 \% \mathrm{PA}$, and total firing time for $20 \% \mathrm{MO}$ content composites showed good results which were $8 \mathrm{sec}, 1 \mathrm{inch}$, and $268 \mathrm{sec}$, respectively. Mechanical properties (tensile strength, tensile modulus, bending strength, bending modulus, and elongation at break), degradation properties (soil test, weathering test, and percentage of weight loss), and water uptake were studied.
\end{abstract}

\section{Introduction}

Composite material means combination of more than one material with various properties. The properties of the composite are different from earlier individual materials. Within the composite [1] it is still feasible to easily tell the isolate materials [2] apart. The materials which are used to produce composite do not tend to blend or absorb each other. Manmade composite materials are available and also they exist in nature $[3,4]$. Fiberglass was the first modern composite and was developed in the late 1940s and is still the most common composite [5]. It fulfills about 65 percent of the demands of all the composites produced today and is used for surfboards, boat hulls, sporting goods, car bodies, swimming pool linings, and building panels.

Peoples have been using composite materials for thousands of years [6], for example, mud bricks. Dried mud is easy to break by bending, which puts a tension force on one edge, but makes a good strong wall, where all the forces are compressive. On the other hand, a piece of straw has a lot of strength when we try to stretch it but almost none when we fold it up. However, if we set pieces of straw in a block of mud and let them dry hard, the resulting mud brick resists both squeezing and tearing and makes an excellent building material. Concrete is another well-known composite. In this case, aggregate (small stones or gravel) is bound together by cement [7]. Concrete has excellent strength under compression, and it can be made stronger under tension by adding metal rods, wires, mesh, or cables to the composite (so creating reinforced concrete).

In any natural fiber, jute is the most commonly obtained composite as an extract from the bark of the jute plant that grows like any other organic crop. Earlier, this fibrous plant was also used by the natives as a delicacy that went along with their staple diet. Bengali name of jute is "Pat" (Patta in Sanskrit) $[8,9]$. But, the appearance of jute as a commercial commodity dates back to the end of the 18th century. At first, the jute fiber was made into ropes 
that were broadly used in the wind and hand driven sea vessels and ships. Afterwards, jute was discovered to have been cut and woven for manufacture of carpets [10]. Newer technologies flourished in 1838 and jute fiber was shorn into better yarn and woven to make jute-cloth. Jute handbags and sacking bags were the inaugural prosperity and with that jute products commenced to go into the daily lives of community. Appliance in packaging and carpet making has also been tamed by jute ever since jute started to be woven into fabric form [11].

At the present time, there is a serious environmental problem with waste disposal, and so forth. It is tenacious to reuse and recycle fiber reinforced composite, glass fiber reinforced composite, and so forth. Natural fibers such as bamboo, kenaf, jute, and hemp fibers are focused on for environmental friendliness rather than glass fibers. The physical properties such as mechanical properties for some natural fiber reinforced composites have been practiced. Activities on green composite are comprehensively progressed. In our research work, jute fibers are used as reinforcement due to low cost and large production. Polypropylene is used as a matrix material because of recycling properties and cost. The mechanical properties for Jute Fiber Reinforced Plastics (JFRP) are studied [12-14]. On the basis of environmental and ecological responsibility, assertion of natural fiber composite is increased day by day. For construction purposes jute PP composite can play an important role all over the world. Jute polypropylene composite can be used for interior design, particle board, ceiling, and construction purposes. Instead of importing particle board and cement we can use jute PP composite. On the other hand jute is cheaper than most of natural fibers. So it is probable to earn a lot of external cash by exporting jute PP composite [15]. Taking into account the expectation of jute PP composite, an eminent emphasis on it is highly necessary. In the previous work it was explored that the probability of decreasing the flammability of flax biopolyester composites using alumina trihydrate, ammonium polyphosphate, and Exolit 740 minimized heat release rate and flammability up to a $60 \%$, delaying the ignition time with respect to the unfilled material [1]. Our research work deals with the betterment of the fire retardant properties of jute polypropylene composite by using different percentage of nonhalogenated fire retardants such as $\mathrm{MgO}$, $\mathrm{Al}_{2} \mathrm{O}_{3}$, and $\mathrm{H}_{3} \mathrm{PO}_{4}$.

\section{Experimental}

2.1. Materials. A hydraulic pressing machine (model: 4128, Carver Inc., Wabash, Indiana, USA) is suitably placed to press the sample inside the die at a particular temperature. The whole die is surrounded with aluminum foil for heat in solution. The heating coil is connected to a variable transformer to control the current through the coil thereby controlling the temperature of the die. A small hole is dug on the middle part of the die near the specimen to put a thermocouple for recording the die temperature. A single screw extrusion machine (model: Axon abNyvang, Sweden) is suitably placed to extrude the sample inside the machine at a particular temperature. A motor is used to maintain the rotation speed. The polypropylene chips are inserted from the hopper. There are five temperature zones in the extruder. These zones are mentioned by zone 1 , zone 2 , zone 3 , zone 4, and zone 5. Various tensile properties (tensile strength, elongation at break, tensile modulus, etc.) and bending properties (bending strength, bending modulus, etc.) can be determined by tensile strength machine (model: H50KS0404, HOUNSFIELD corporation).

Polypropylene (PP) was purchased from Polyolefin Company, Pvt. Ltd., Singapore. Magnesium oxide (Bayer, Germany), aluminum oxide (Bayer, Germany), and phosphoric acid (BASF, Germany) were used as chemicals. Jute (bleached Hessian cloth) was collected from local market.

2.2. Methods. Hessian cloth was cut by scissors into $2-5 \mathrm{~mm}$ sections. Then definite weight of Hessian cloth was taken in a beaker and kept it in an oven for ten minutes for remove the moisture. The temperature of the oven was kept at $55^{\circ} \mathrm{C}$. Then a definite weight of polypropylene was taken in another beaker. Then $20 \mathrm{~g}$ of moisture-free jute, $70 \mathrm{~g}$ of polypropylene, and $10 \mathrm{~g}$ of $\mathrm{MgO}$ powder were mixed with each other. Thus $10 \% \mathrm{MgO}$ sample was produced. In such a way 20 and $30 \%$ of $\mathrm{MgO}$ sample and 10,20 , and $30 \% \mathrm{Al}_{2} \mathrm{O}_{3}$ sample were produced. $10 \mathrm{~mL}$ of $\mathrm{H}_{3} \mathrm{PO}_{4}$ was mixed with $90 \mathrm{~mL}$ of water. Then $10 \% \mathrm{H}_{3} \mathrm{PO}_{4}$ aqueous solution was produced. Then short jute fiber was soaked in this solution for 5 minutes and kept it for 2 minutes in an oven for drying. In such a way 20 and $30 \% \mathrm{H}_{3} \mathrm{PO}_{4}$ soaked short jute fiber sample was produced.

The mixture of short jute fiber, polypropylene, and nonhalogenated fire retardants materials were used to make a composite. Here single screw extrusion machine was used. There are 5 temperature zones. The temperature started from $185^{\circ} \mathrm{C}, 190^{\circ} \mathrm{C}, 195^{\circ} \mathrm{C}, 200^{\circ} \mathrm{C}$, and $205^{\circ} \mathrm{C}$. The rotation speed was $19.04 \mathrm{~Hz}$. At first the mixture was filled in the hopper of extruder. Then the hot mould came out. In such a way the mould was obtained from four passes. Finally the mould was collected from a stainless steel plate and another plate was covered by it and it entered the hydraulic press machine for cold press. After cold press, composites were prepared. Both treated and untreated jute were used to make composites in this way. The composites fabrication conditions are as follows:

(1) Temperature: $185^{\circ} \mathrm{C}-205^{\circ} \mathrm{C}$

(2) Rotation speed: $19.04 \mathrm{~Hz}$

(3) Pass: 4 times

(4) Cold pressure: 6 tons

(5) Cooling time: 5 minutes.

Composites sheets were cut into pieces of $10 \mathrm{~mm}$ width for the determination of tensile strength, bending strength, and bending modulus.

\section{Results}

In the present work investigations of the fire retardants effects on short jute fiber polypropylene composites were carried out. The short jute fibers and polypropylene were mixed with 10,20 , and $30 \%$ of magnesium oxide (MgO) and 


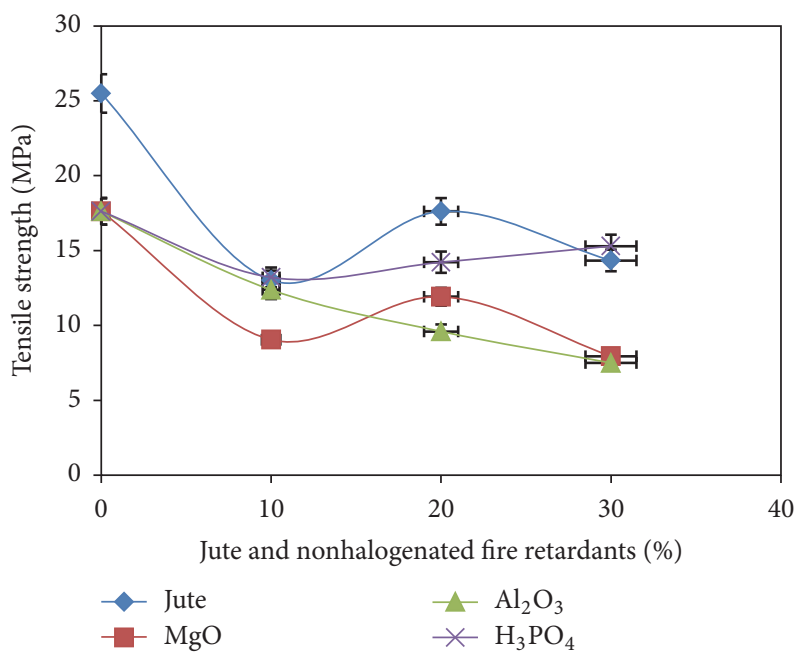

Figure 1: Untreated jute composites and $\mathrm{MgO}, \mathrm{Al}_{2} \mathrm{O}_{3}$, and $\mathrm{H}_{3} \mathrm{PO}_{4}$ treated jute composites versus tensile strength ( $\mathrm{MPa})$.

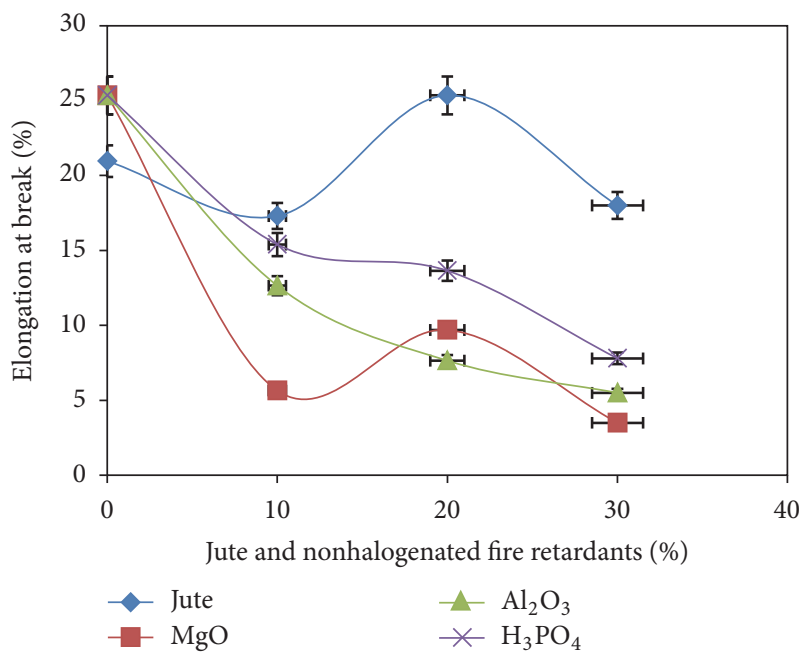

Figure 2: Untreated jute composites and $\mathrm{MgO}, \mathrm{Al}_{2} \mathrm{O}_{3}$, and $\mathrm{H}_{3} \mathrm{PO}_{4}$ treated jute composites versus elongation at break (\%).

aluminum oxide $\left(\mathrm{Al}_{2} \mathrm{O}_{3}\right)$; also jute fibers were treated with aqueous phosphoric acid $\left(\mathrm{H}_{3} \mathrm{PO}_{4}\right)$ by soaking method. Here soaking time was $5 \mathrm{~min}$ and the treatment of short jute fiber was carried out at room temperature. Fire retardants short jute fiber polypropylene composites were prepared by single screw extrusion method. Various fire retardancy properties like ignition time, flame height, and total firing time were measured. Mechanical properties of the composites such as tensile strength, tensile modulus, and elongation at break, bending strength, and bending modulus were also measured and degradation properties such as soil and weathering test, percentage of weight loss, and water uptake were also observed.

Figures 1-5 show mechanical properties such as tensile strength, tensile modulus, and elongation at break, bending strength, and bending modulus of magnesium oxide $(\mathrm{MgO})$ and aluminum oxide $\left(\mathrm{Al}_{2} \mathrm{O}_{3}\right)$ and phosphoric acid $\left(\mathrm{H}_{3} \mathrm{PO}_{4}\right)$

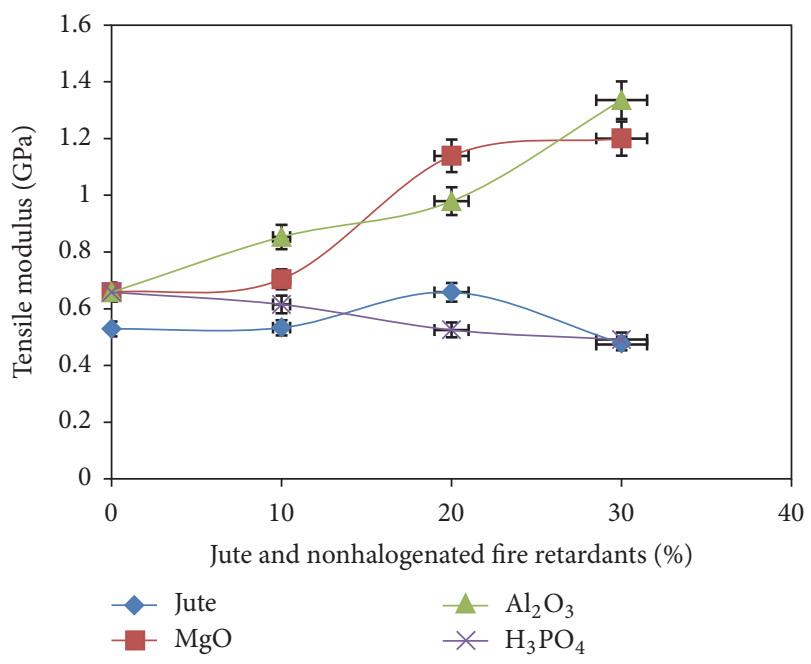

Figure 3: Untreated jute composites and $\mathrm{MgO}, \mathrm{Al}_{2} \mathrm{O}_{3}$, and $\mathrm{H}_{3} \mathrm{PO}_{4}$ treated jute composites versus tensile modulus (GPa).

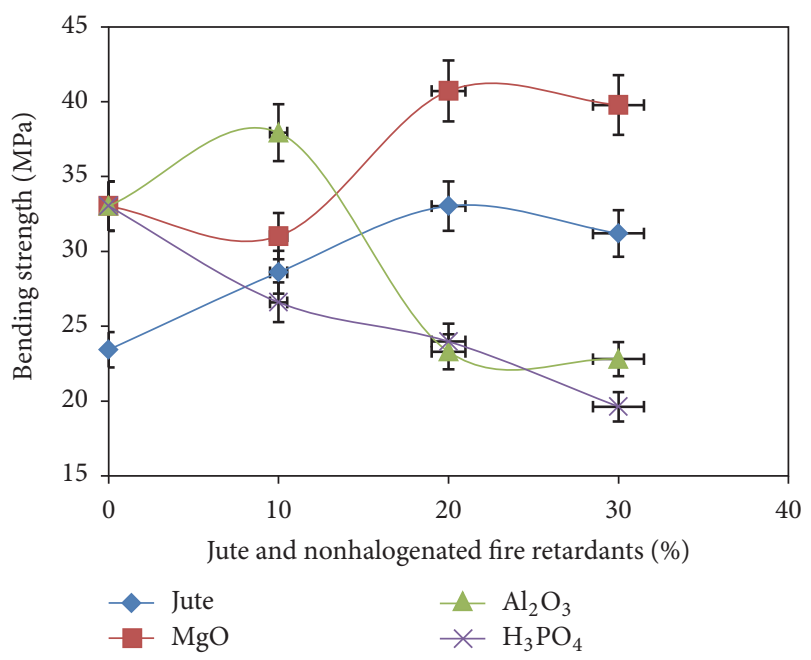

FIgURE 4: Untreated jute composites and $\mathrm{MgO}, \mathrm{Al}_{2} \mathrm{O}_{3}$, and $\mathrm{H}_{3} \mathrm{PO}_{4}$ treated jute composites versus bending strength $(\mathrm{MPa})$.

fire retardants treated short jute fibers composites. Magnesium oxide and aluminum oxide $\left(\mathrm{Al}_{2} \mathrm{O}_{3}\right)$ fire retardants treated short jute fiber composites had lower mechanical properties than the untreated jute composites for maximum cases.

Here aluminum oxide acts as a doping material. 10\% aluminum oxide showed the highest tensile strength $(12.38 \mathrm{MPa})$, elongation at break $(12.65 \%)$, bending strength $(37.93 \mathrm{MPa})$, and bending modulus $(1.68 \mathrm{GPa})$ compared to other percentages of aluminum oxide treated composites. And $30 \%$ aluminum oxide treated composites had the highest tensile modulus (1.335 GPa). But aluminum oxide treated composites had better results of bending strength and tensile modulus than untreated jute composites.

Phosphoric acid $\left(\mathrm{H}_{3} \mathrm{PO}_{4}\right)$ fire retardants treated short jute fibers composites had lower mechanical properties than the untreated jute composites for all cases because phosphoric 


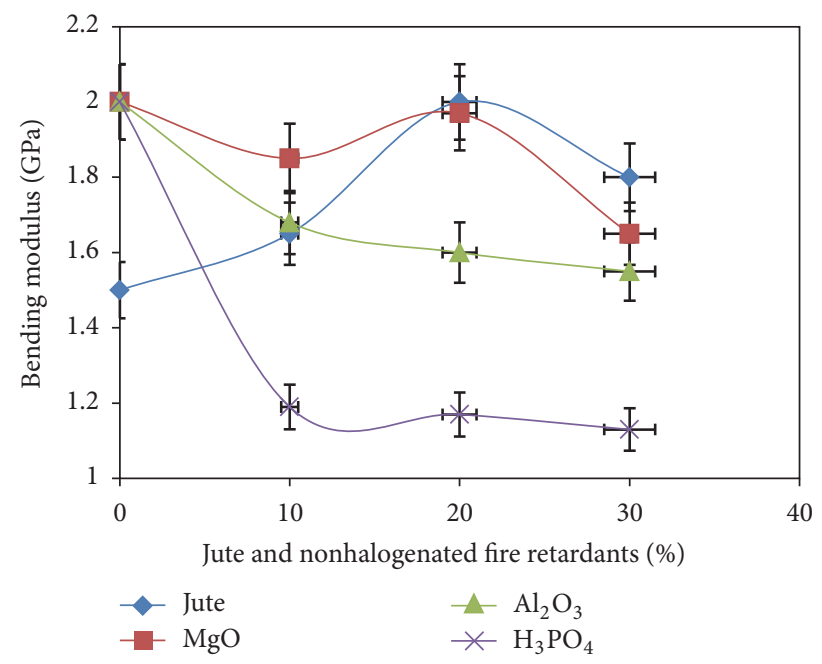

Figure 5: Untreated jute composites and $\mathrm{MgO}, \mathrm{Al}_{2} \mathrm{O}_{3}$, and $\mathrm{H}_{3} \mathrm{PO}_{4}$ treated jute composites versus bending modulus $(\mathrm{GPa})$.

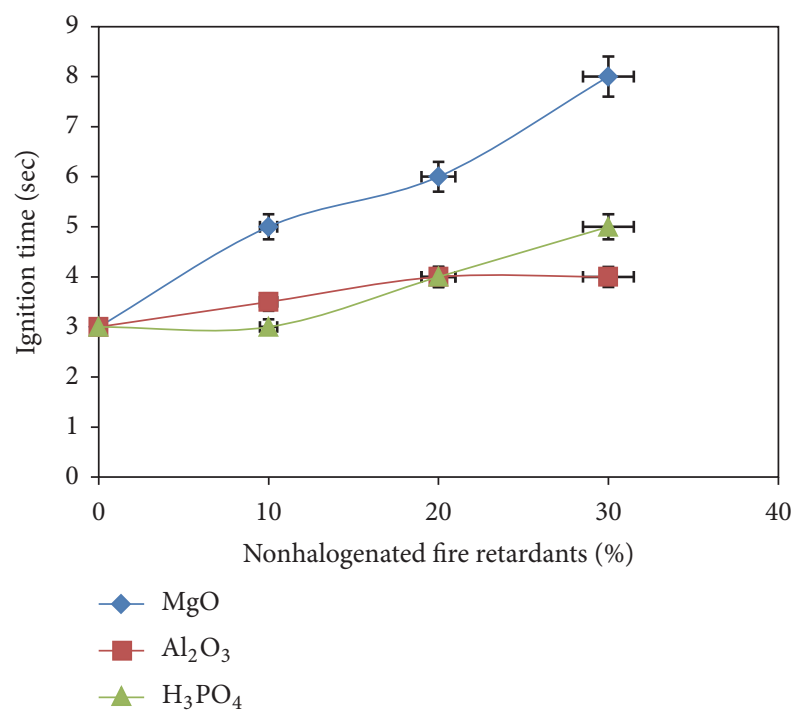

Figure 6: Untreated and $\mathrm{MgO}, \mathrm{Al}_{2} \mathrm{O}_{3}$, and $\mathrm{H}_{3} \mathrm{PO}_{4}$ treated jute composites versus ignition time (sec).

acids break the cellulosic bond of short jute fibers. In that case mechanical properties were decreased. $10 \%$ phosphoric acid had the highest elongation at break $(15.40 \%)$, tensile modulus (0.615 GPa), bending strength (26.6 MPa), and bending modulus (1.19 GPa) compared to other percentages of phosphoric acid treated composites. And 30\% phosphoric acid treated composites had highest tensile strength (15.30 MPa).

Figure 6 showed untreated and $\mathrm{MgO}, \mathrm{Al}_{2} \mathrm{O}_{3}$, and $\mathrm{H}_{3} \mathrm{PO}_{4}$ treated jute composites versus ignition time (sec). Ignition time of polypropylene was $2 \mathrm{sec}$. Then short jute fiber polypropylene composites or $0 \%$ jute content composites ignition time was observed. Its shown time period for ignition was $3 \mathrm{sec}$. Then magnesium oxide, aluminum oxide, and phosphoric acid fire retardants of 10,20 , and $30 \%$ composites were investigated. Among them $30 \%$ magnesium oxide had

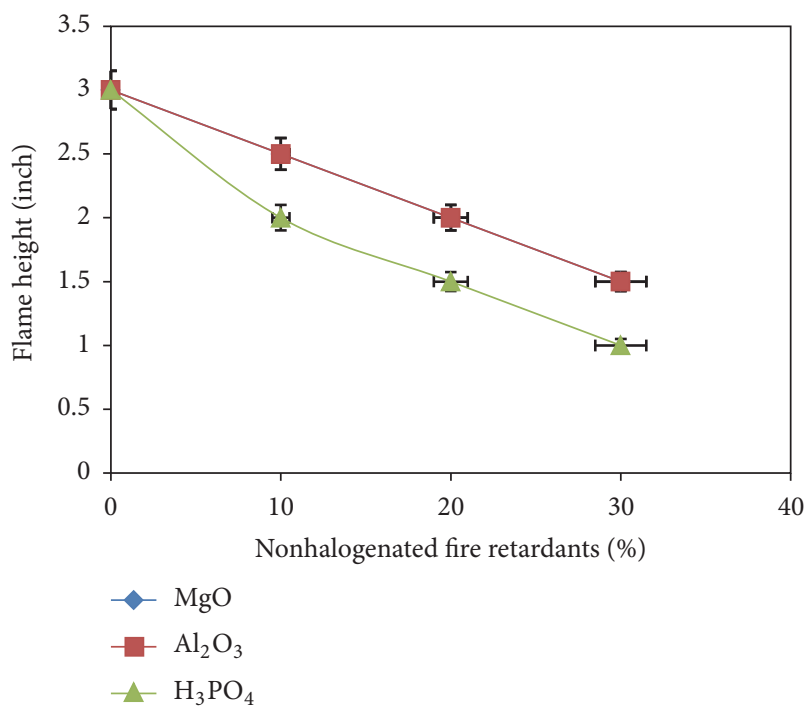

Figure 7: Untreated and $\mathrm{MgO}, \mathrm{Al}_{2} \mathrm{O}_{3}$, and $\mathrm{H}_{3} \mathrm{PO}_{4}$ treated jute composites versus flame height (inch).

highest result which was $8 \mathrm{sec}$, whereas $10 \%$ phosphoric acid showed minimum results because $3 \mathrm{sec}$ were required. Again $4 \mathrm{sec}$ were required for 20 and $30 \%$ aluminum oxide.

Figure 7 showed flame height of polypropylene and $0 \%$ of jute content composites. Its showed flame height of 4 and 3 inches, respectively. Then magnesium oxide, aluminum oxide, and phosphoric acid fire retardants of 10, 20, and $30 \%$ composites were investigated. They had almost the same result. The highest flame height was 2.5 inches and it was given by both $10 \%$ magnesium oxide and aluminum oxide and lowest flame height showed 30\% phosphoric acid and it was 1 inch.

Total firing time of polypropylene and $0 \%$ of jute content composites is investigated. Total firing time of 120 and $191 \mathrm{sec}$, respectively, was shown. Then magnesium oxide, aluminum oxide, and phosphoric acid fire retardants of 10,20 , and $30 \%$ composites were investigated. Among them $20 \%$ magnesium oxide had the highest result required $(268 \mathrm{sec}$ ) and 30\% phosphoric acid had the lowest time required $(185 \mathrm{sec}) .10 \%$ aluminum oxide showed moderately good result and it was $240 \mathrm{sec}$ (Figure 8).

The various percentages of fire retardants treated jute composites and untreated composites were placed in soil for 30 days. After 30 days the composites samples were picked up and various mechanical properties were investigated. Then untreated jute composites had tensile strength, tensile modulus, and elongation at break of $13.8 \mathrm{MPa}, 11.6 \%$, and $0.587 \mathrm{GPa}$, respectively. $30 \%$ phosphoric acid, $10 \%$ phosphoric acid, and $30 \%$ aluminum oxide had the highest value of tensile strength (13.4 MPa), elongation at break (14.2\%), and tensile modulus (0.978 GPa). 30\% aluminum oxide, magnesium oxide, and phosphoric acid had lowest value of tensile strength $(5.82 \mathrm{MPa})$, elongation at break $(2.1 \%)$, and tensile modulus $(0.25 \mathrm{GPa})$, respectively (Figures $9-11)$. After soil test the mechanical properties were seriously decreased. 


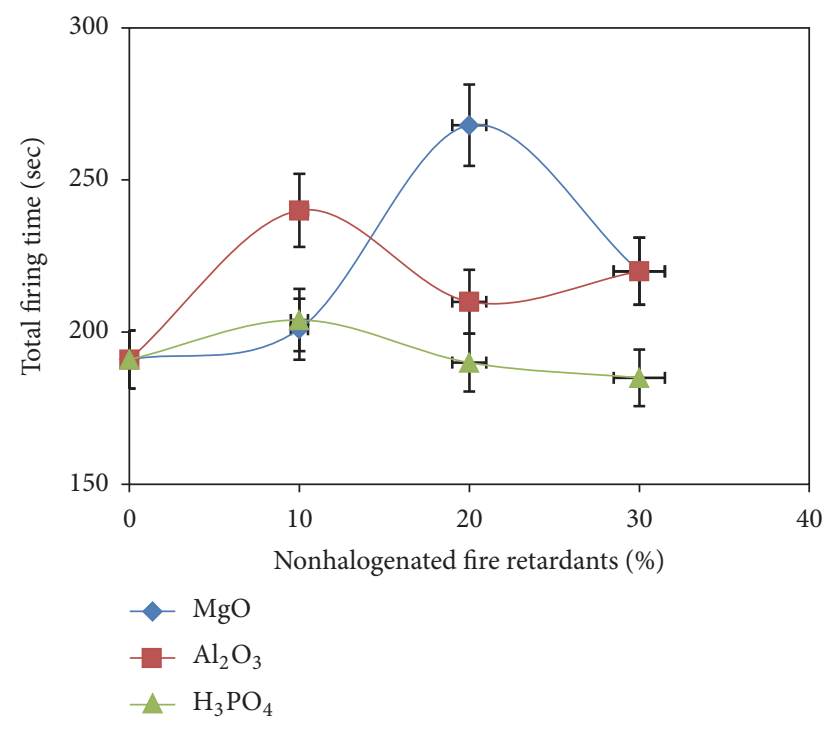

Figure 8: Untreated and $\mathrm{MgO}, \mathrm{Al}_{2} \mathrm{O}_{3}$, and $\mathrm{H}_{3} \mathrm{PO}_{4}$ treated jute composites versus total firing time (sec).

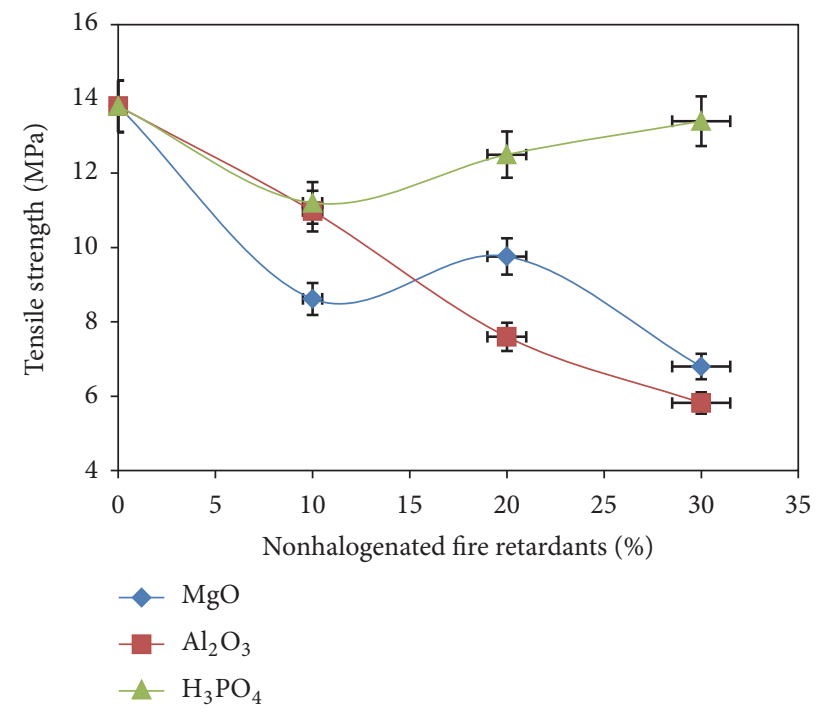

FIgURE 9: Tensile strength $(\mathrm{MPa})$ of untreated and treated jute composites in soil for 30 days.

After 30 days of soil test the treated and untreated samples were weighted. Before soiling the samples were also weighted. Weight loss was calculated using the weight difference. Untreated jute composites lost $2.65 \%$ of weight. Among the treated composites, 30\% magnesium oxide lost the highest weight (6.1\%) and 20\% phosphoric acid lost the lowest weight (1.34\%) (Figure 12).

The various percentages of fire retardants treated jute composites and untreated composites were placed in weathering machine for 50 hours. After 50 hours the composites samples were picked up and various mechanical properties were investigated. Then untreated jute composites had tensile strength, tensile modulus, and elongation at break of 7.43 $\mathrm{MPa}, 15.5 \%$, and $0.616 \mathrm{GPa}$, respectively. $30 \%$ phosphoric

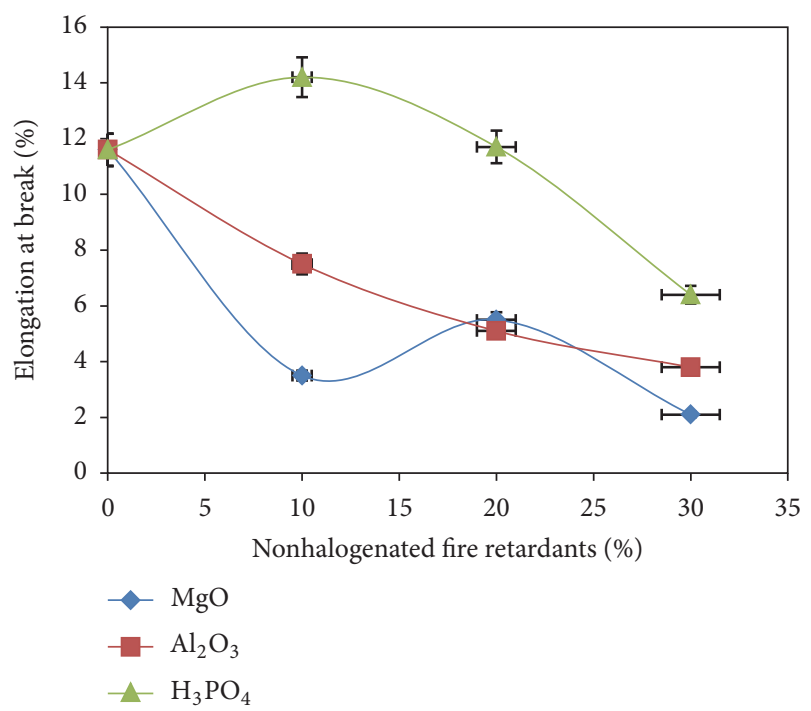

FIGURE 10: Elongation at break (\%) of untreated and treated jute composites in soil for 30 days.

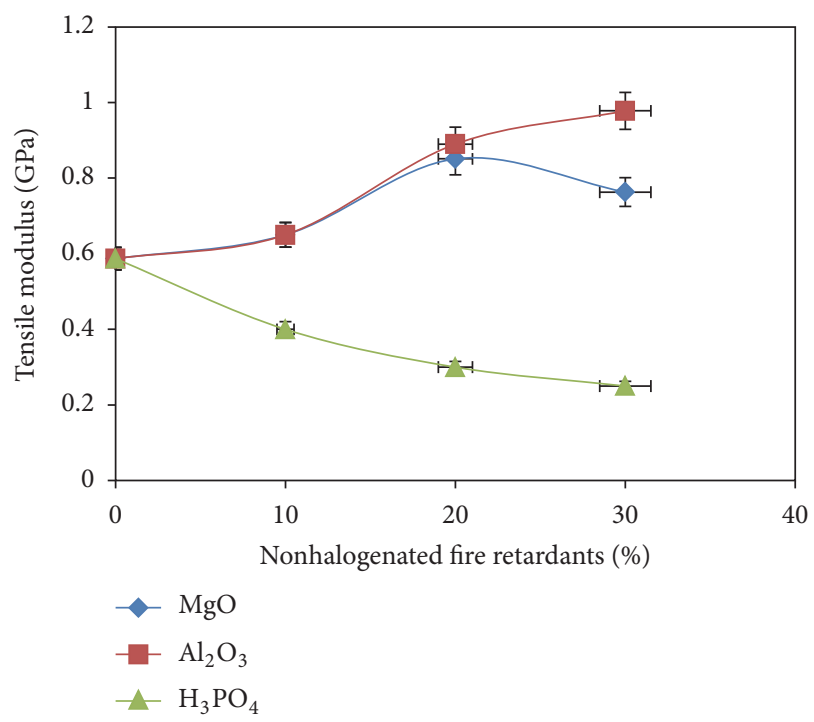

FIGURE 11: Tensile modulus (GPa) of untreated and treated jute composites in soil for 30 days.

acid, $10 \%$ phosphoric acid, and $30 \%$ aluminum oxide showed the highest value of tensile strength $(14.5 \mathrm{MPa})$, elongation at break (12.5\%), and tensile modulus (1.213 GPa). $30 \%$ aluminum oxide, magnesium oxide, and phosphoric acid had the lowest value of tensile strength (5.82 MPa), elongation at break (3.5\%), and tensile modulus (0.39 GPa) (Figures 13-15). After weathering test the mechanical properties were moderately decreased. After 50 hours of weathering test the treated and untreated samples were weighted. Before weathering the samples were also weighted. Weight loss was estimated from the weight difference. Untreated jute composites lost $0.86 \%$ of weight. Among the treated composites, $20 \%$ aluminum oxide lost the highest weight $(2.24 \%)$ and $10 \%$ phosphoric acid lost the lowest weight $(0.57 \%)$ (Figure 16$)$. 


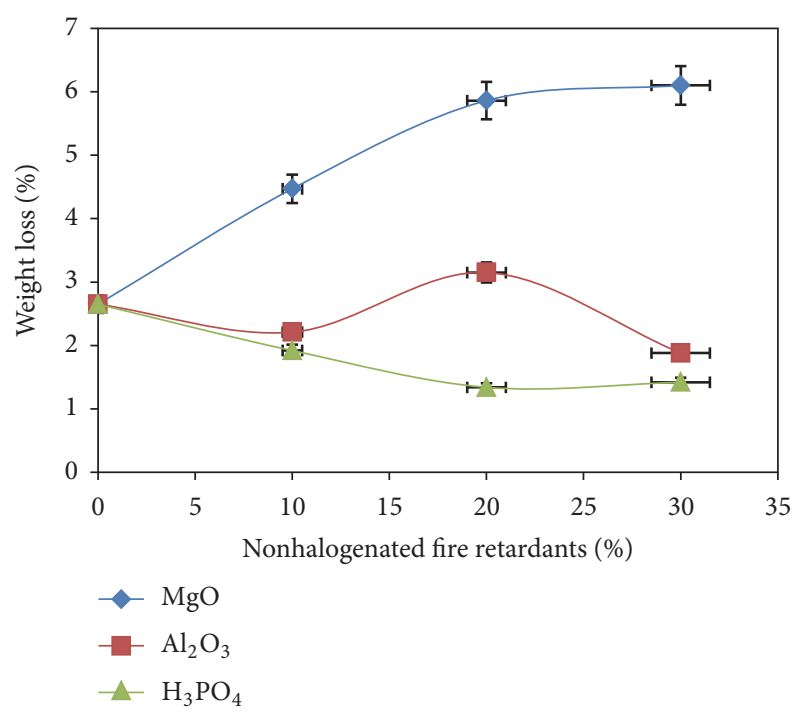

FIGURE 12: \% of weight loss of untreated and treated jute composites in soil for 30 days.

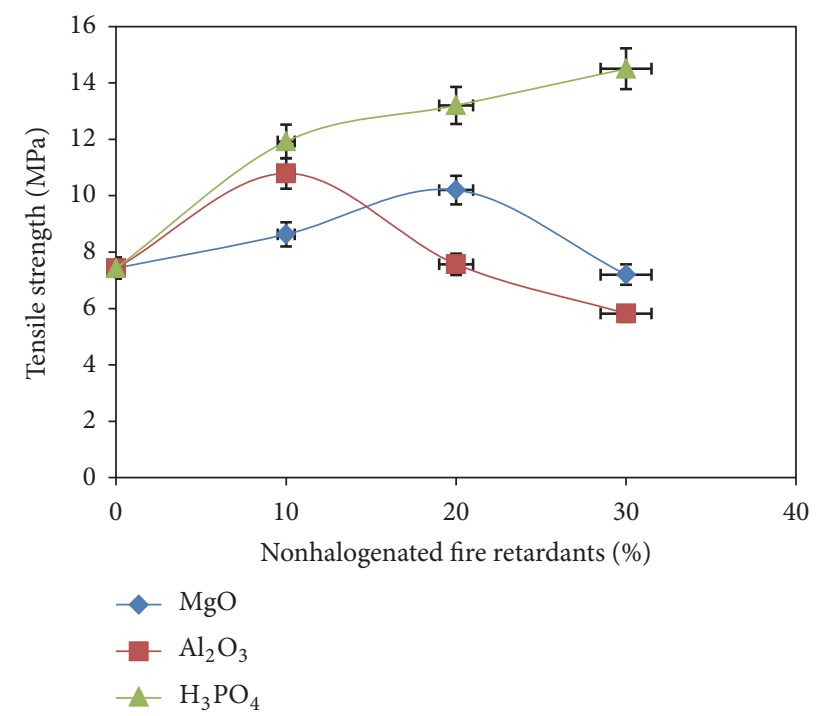

Figure 13: Tensile strength (MPa) of untreated and treated jute composites in weathering machine for 50 hours.

Various percentages of fire retardants treated jute composites and untreated composites were cut at a constant dimension and soaked in water. The difference between the periods after and before soaking water uptake is investigated. Untreated jute composites shown at the end of time period has $0.168 \%$ water uptake. Among the treated composites, the highest and lowest value of water uptake showed $20 \%$ magnesium oxide and $30 \%$ phosphoric acid of 1.14 and $0.14 \%$, respectively (Figures 17-19).

\section{Discussion}

In case of untreated jute fiber, $80 \%$ polypropylene and $20 \%$ short jute fiber reinforced composites showed the highest

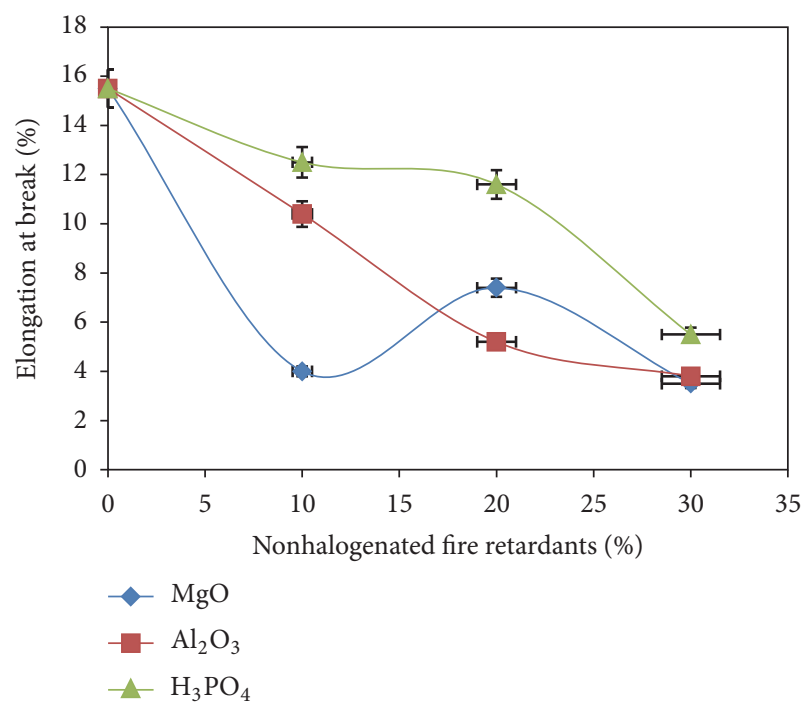

FIGURE 14: Elongation at break (\%) of untreated and treated jute composites in weathering machine for 50 hours.

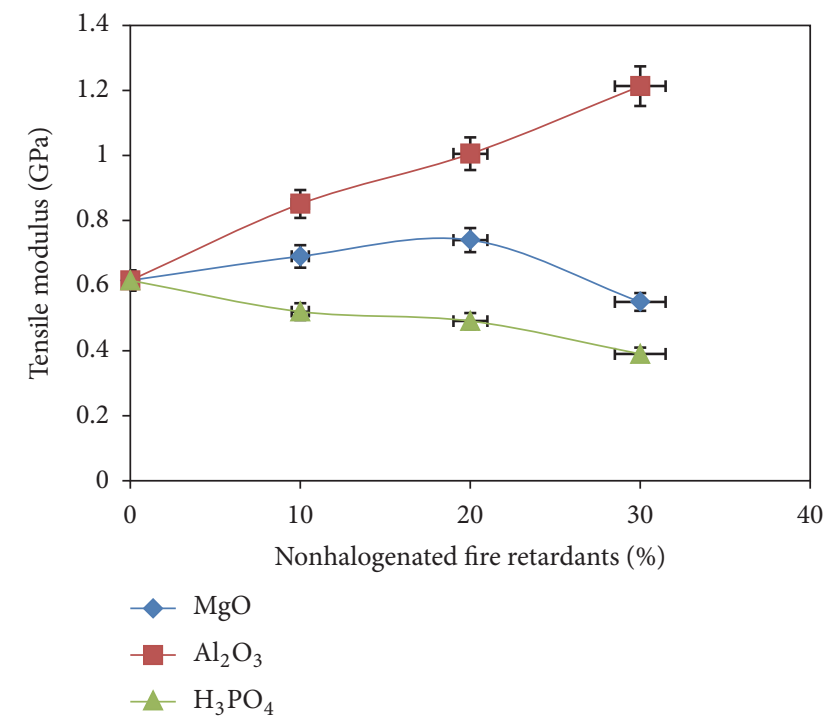

Figure 15: Tensile modulus (GPa) of untreated and treated jute composites in weathering machine for 50 hours.

mechanical properties. Based on the optimization, in order to find out the fire retardant properties such as ignition time, flame height, and total firing time of the composites, different percentages of $\mathrm{MgO}, \mathrm{Al}_{2} \mathrm{O}_{3}$, and $\mathrm{H}_{3} \mathrm{PO}_{4}$ were used. Comparison of various properties of untreated and treated short jute fiber composites was analyzed.

Magnesium oxide and aluminum oxide act as doping materials but phosphoric acid interrupts the cellulosic bond of short jute fibers. 20\% magnesium oxide had the highest tensile strength $(11.92 \mathrm{MPa})$, elongation at break (9.7\%), bending strength $(40.72 \mathrm{MPa})$, and bending modulus (1.97 GPa) compared to other percentages of magnesium oxide treated composites. And 30\% magnesium oxide treated composites had the highest tensile modulus (1.2 GPa). But 


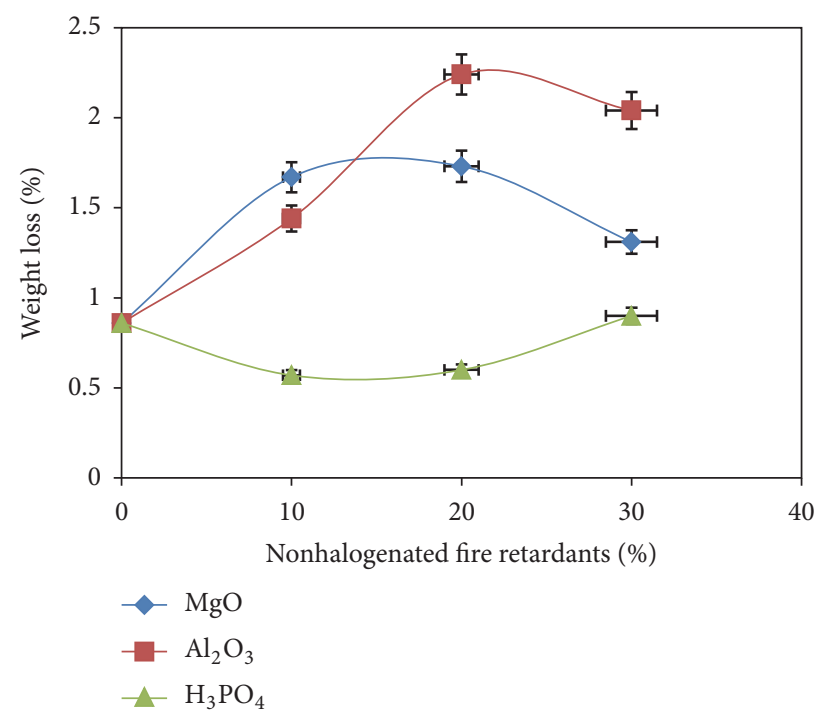

FIGURE 16: \% of weight loss of untreated and treated jute composites in weathering machine for 50 hours.

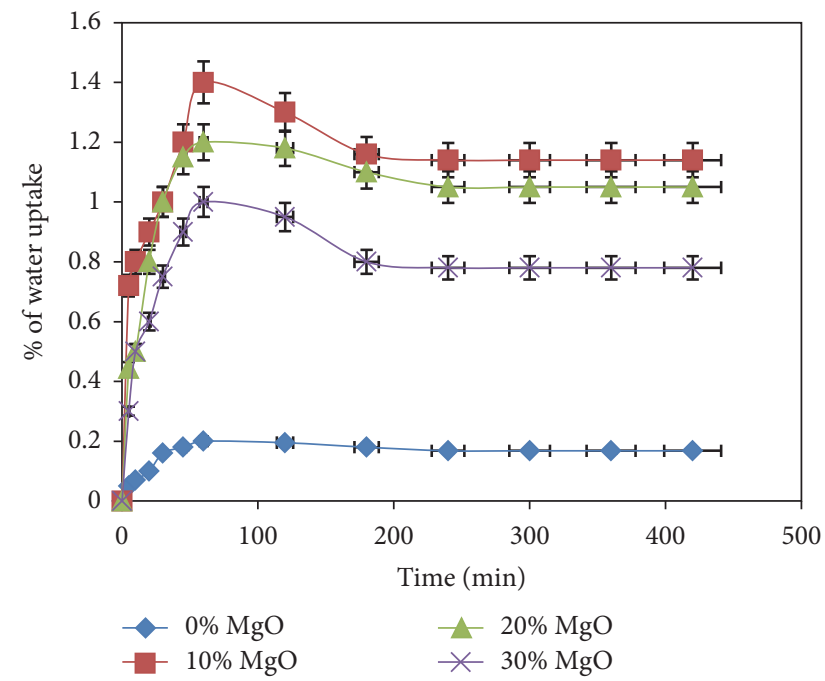

Figure 17: Comparison curve for water uptake of untreated and $\mathrm{MgO}$ treated jute composites.

magnesium oxide treated composites had better results of bending strength and tensile modulus than untreated jute composites. Flame height of $30 \%$ phosphoric acid treated composites expressed the lowest value (1 inch) compared to other treated composites. $20 \%$ magnesium oxide treated composites showed the highest water uptake value (1.14\%) whereas $30 \%$ phosphoric acid expressed the lowest water uptake value $(0.14 \%)$.

\section{Conclusion}

To increase the fire retardant properties of short jute fiber polypropylene composites, magnesium oxide $(\mathrm{MgO})$, aluminum oxide $\left(\mathrm{Al}_{2} \mathrm{O}_{3}\right)$, and aqueous phosphoric acid $\left(\mathrm{H}_{3} \mathrm{PO}_{4}\right)$ were used as nonhalogenated fire retardants. The

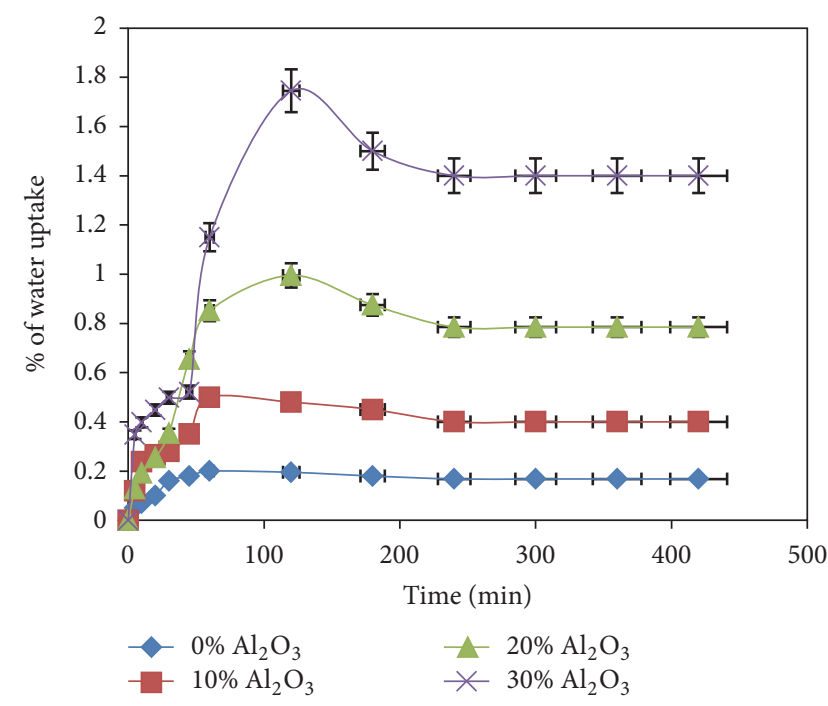

FIGURE 18: Comparison curve for water uptake of untreated and $\mathrm{Al}_{2} \mathrm{O}_{3}$ treated jute composites.

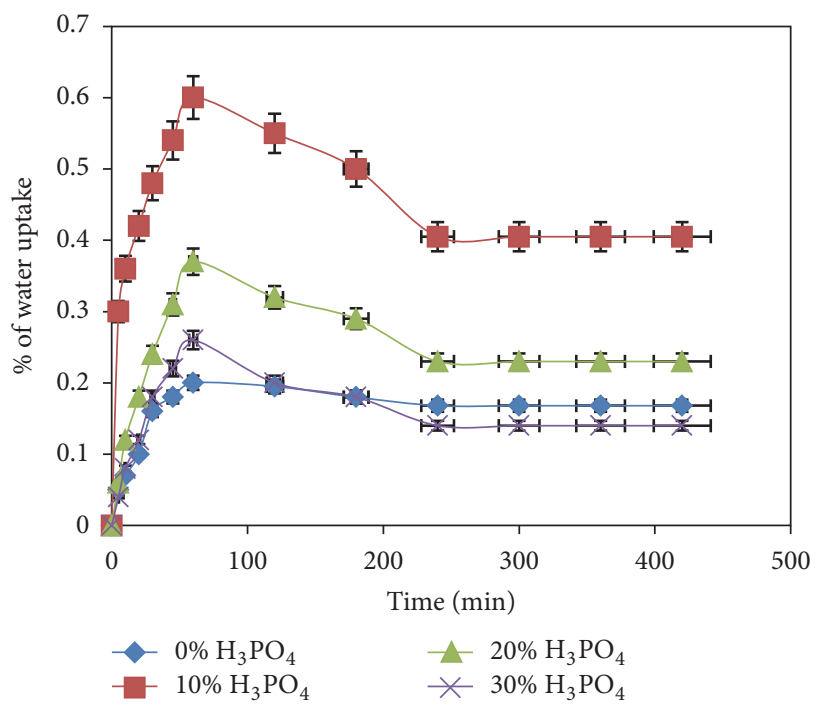

FIGURE 19: Comparison curve for water uptake of untreated and $\mathrm{H}_{3} \mathrm{PO}_{4}$ treated jute composites.

fire retardants were used in different percentages as 10, 20, and $30 \%$. Compared with untreated short jute fiber polypropylene composites, the fire retardant properties of $\mathrm{MgO}, \mathrm{Al}_{2} \mathrm{O}_{3}$, and $\mathrm{H}_{3} \mathrm{PO}_{4}$ treated composites were improved. $30 \% \mathrm{MgO}$, $\mathrm{Al}_{2} \mathrm{O}_{3}$, and $\mathrm{H}_{3} \mathrm{PO}_{4}$ composites had a good result for ignition time and flame height and $20 \% \mathrm{MgO}, 10 \% \mathrm{Al}_{2} \mathrm{O}_{3}$, and $10 \%$ $\mathrm{H}_{3} \mathrm{PO}_{4}$ composites had a good result for total firing time. Mechanical properties (tensile strength, tensile modulus, elongation at break, bending strength, and bending modulus) of treated composites decrease compared to untreated composites. After weathering and soil test, the mechanical properties of the composites also decreased with respect to those before soiling and weathering and also percentage of weight loss of treated composites was minimum. Percentage of water uptake of treated composites was around 0.4 to 
1.45\%. As the fire retardant properties increase for short jute fiber polypropylene composites, this has great prospects for commercial uses, such as making household articles like chair, table, and inner decoration and bodies of buses, cars, trains, and aircrafts. Composites materials are easily ignitable. So, using fire retardants, they would be minimized. For reducing the combustible properties of composites, fire retardants are very important.

\section{Conflicts of Interest}

The authors declare that they have no conflicts of interest.

\section{References}

[1] N. U. Loredo and J. S. Bermejo, "Enhanced flame retardancy of flax bio-composites for the construction market," Journal of Facade Design and Engineering, vol. 4, no. 1-2, pp. 67-76, 2016.

[2] F. Rault, S. Giraud, F. Salaün, and X. Almeras, "Development of a halogen free flame retardant masterbatch for polypropylene fibers," Polymers, vol. 7, no. 2, pp. 220-234, 2015.

[3] L. Zhou, Y. Ju, F. Liao, Y. Yang, and X. Wang, "Improve the mechanical property and flame retardant efficiency of the composites of poly(lactic acid) and resorcinol di(phenyl phosphate) (RDP) with ZnO-coated kenaf," Fire and Materials, vol. 40, no. 1, pp. 129-140, 2016.

[4] S. Bhattacharjee, M. H. Sazzad, M. A. Islam et al., "Effects of fire retardants on jute fiber reinforced polyvinyl chloride/polypropylene hybrid composites," International Journal of Materials Science and Applications, vol. 2, no. 5, pp. 162-167, 2013.

[5] V. N. Haruna, A. S. Abdulrahman, P. T. Zubairu, L. O. Isezuo, M. A. Abdulrahman, and D. C. Onuoha, "Prospects and challenges of composites in a developing country," ARPN Journal of Engineering and Applied Sciences, vol. 9, no. 7, pp. 1069-1075, 2014.

[6] M. Nikolaeva and T. Kärki, "Influence of fire retardants on the reaction-to-fire properties of coextruded wood-polypropylene composites," Fire and Materials, vol. 40, no. 4, pp. 535-543, 2016.

[7] G. Basu, A. K. Sinha, and S. N. Chattopadhyay, "Proper ties of jute based ternary blended bulked yarns," Man-Made Textiles in India, vol. 48, no. 9, pp. 350-353, 2005.

[8] S. N. Chattopadhyay, N. C. Pan, and A. Day, "A novel process of dyeing of jute fabric using reactive dye," Textile Industry of India, vol. 42, no. 9, pp. 15-22, 2004.

[9] M. R. Rahman, M. Hasan, M. M. Huque, and M. N. Islam, "Physico-mechanical properties of jute fiber reinforced polypropylene composites," Journal of Reinforced Plastics and Composites, vol. 29, no. 3, pp. 445-455, 2009.

[10] M. J. Jeyakodi and M. Ramasamy, "Quality improvement on jute and jute cotton materials using enzyme treatment and natural dyeing," Man-Made Textiles in India, vol. 47, no. 7, pp. 252-255, 2004.

[11] N. T. Phuong and V. Gilbert, "Non-isothermal crystallization kinetics of short bamboo fiber-reinforced recycled polypropylene composites," Journal of Reinforced Plastics and Composites, vol. 29, no. 17, pp. 2576-2591, 2010.

[12] H. Li and M. H. Sain, "High stiffness natural fiber reinforced hybrid polypropylene composite," Polymer-Plastics Technology and Engineering, vol. 42, no. 5, pp. 853-862, 2003.
[13] M. M. Hasan, M. R. Islam, S. Shehzade, and M. A. Khan, "Influence of mercerization with UV and Gamma radiation on the physical and mechanical properties of jute yarn grafted with 3(Trimethoxysilyl) Propylmethacrylate (silane) and Acryamide under UV radiation," Polymer-Plastics Technology and Engineering, vol. 42, no. 4, pp. 515-531, 2003.

[14] S. J. Eichhorn and R. J. Young, "Deformation micromechanics of natural cellulose fiber networks and composites," Composites Science and Technology, vol. 63, no. 9, pp. 1225-1230, 2003.

[15] S. Siddika, F. Mansura, M. Hasan, and A. Hassan, "Effect of reinforcement and chemical treatment of fiber on the properties of jute-coir fiber reinforced hybrid polypropylene composites," Fibers and Polymers, vol. 15, no. 5, pp. 1023-1028, 2014. 

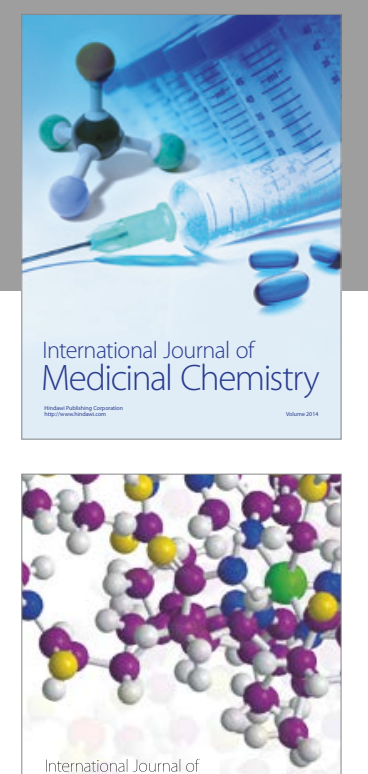

Carbohydrate Chemistry

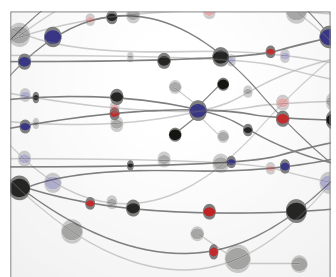

The Scientific World Journal
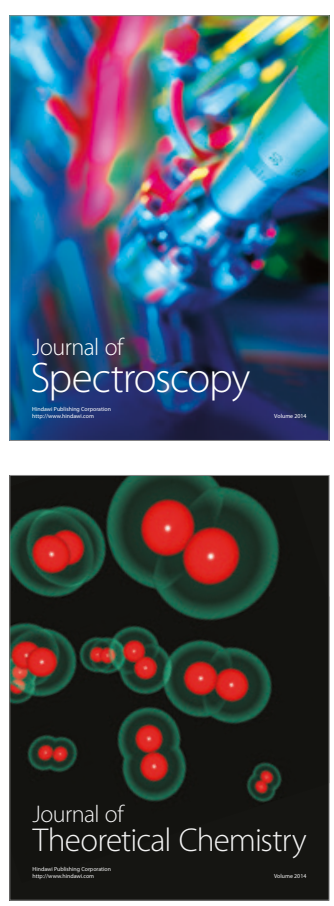
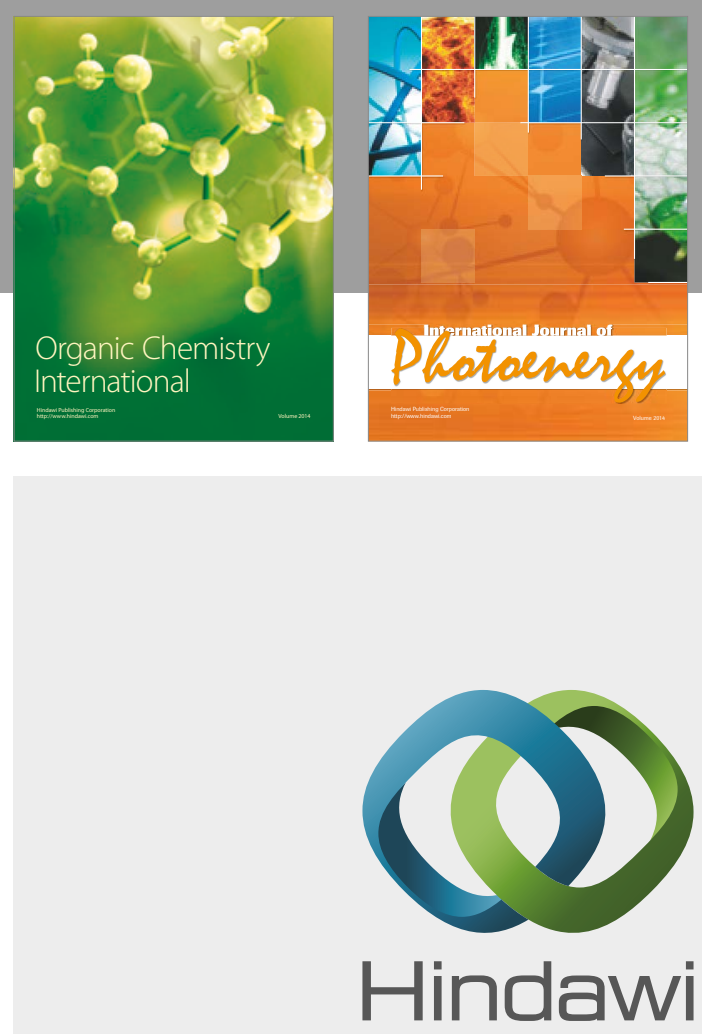

Submit your manuscripts at

https://www.hindawi.com

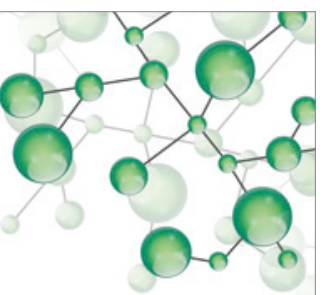

International Journal of

Inorganic Chemistry

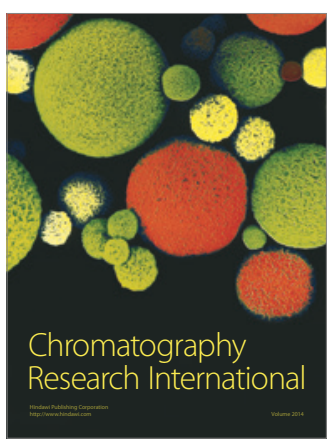

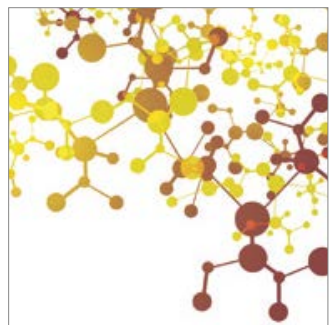

Applied Chemistry
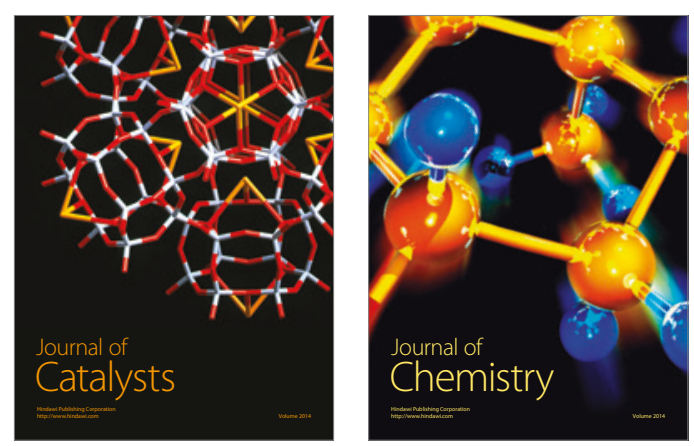
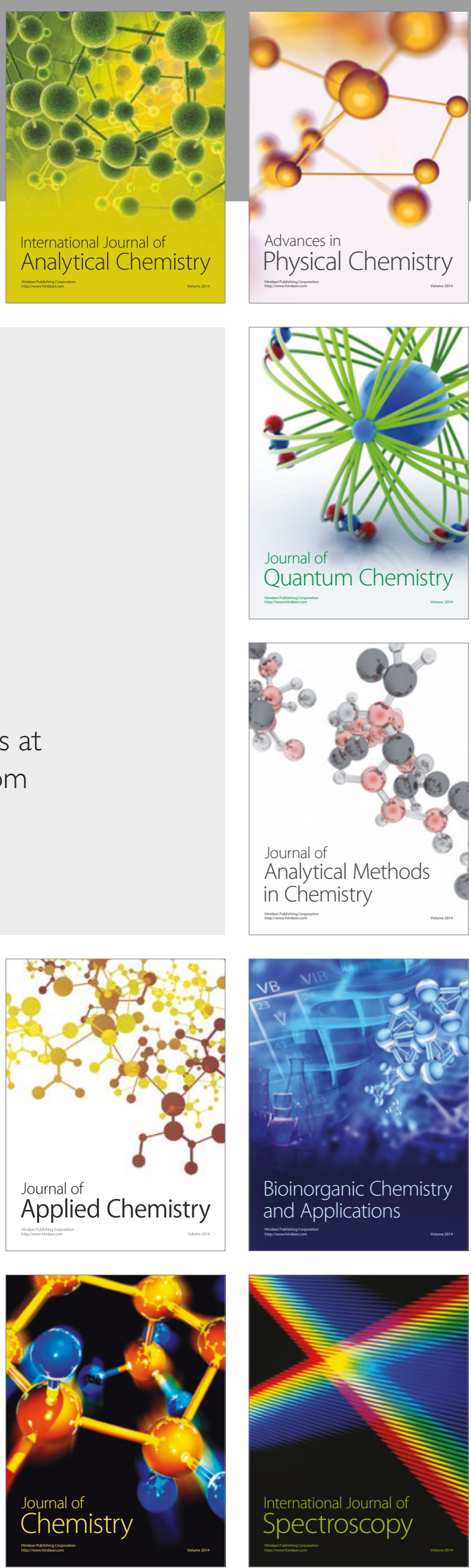